\title{
Reinforcement of Multiwalled Carbon Nanotube in Nitrile Rubber: In Comparison with Carbon Black, Conductive Carbon Black, and Precipitated Silica
}

\author{
Atip Boonbumrung, ${ }^{1}$ Pongdhorn Sae-oui, ${ }^{2}$ and Chakrit Sirisinha ${ }^{1,3}$ \\ ${ }^{1}$ Department of Chemistry, Faculty of Science, Mahidol University, Bangkok 10400, Thailand \\ ${ }^{2}$ MTEC, National Science and Technology Development Agency, Pathumthani 12120, Thailand \\ ${ }^{3}$ Rubber Technology Research Centre (RTEC), Faculty of Science, Mahidol University, Salaya Campus, Nakhon Pathom 73170, Thailand \\ Correspondence should be addressed to Chakrit Sirisinha; chakrit.sir@mahidol.ac.th
}

Received 7 September 2015; Accepted 10 January 2016

Academic Editor: Claude Estournès

Copyright (C) 2016 Atip Boonbumrung et al. This is an open access article distributed under the Creative Commons Attribution License, which permits unrestricted use, distribution, and reproduction in any medium, provided the original work is properly cited.

\begin{abstract}
The properties of nitrile rubber (NBR) reinforced by multiwalled carbon nanotube (MWCNT), conductive carbon black (CCB), carbon black (CB), and precipitated silica (PSi) were investigated via viscoelastic behavior, bound rubber content, electrical properties, cross-link density, and mechanical properties. The filler content was varied from 0 to $15 \mathrm{phr}$. MWCNT shows the greatest magnitude of reinforcement considered in terms of tensile strength, modulus, hardness, and abrasion resistance followed by CCB, $\mathrm{CB}$, and PSi. The MWCNT filled system also exhibits extremely high levels of filler network and trapped rubber even at relatively low loading $(5 \mathrm{phr})$ leading to high electrical properties and poor dynamic mechanical properties. Although CCB possesses the highest specific surface area, it gives lower level of filler network than MWCNT and also gives the highest elongation at break among all fillers. Both CB and PSi show comparable degree of reinforcement which is considerably lower than CCB and MWCNT.
\end{abstract}

\section{Introduction}

NBR is used in numerous applications where high resistance to hydrocarbon oil is required such as fuel hoses, o-rings, gaskets, and industrial rolls. Unfortunately NBR is not crystallizable under high strain, and therefore the reinforcing fillers such as carbon black (CB) and precipitated silica (PSi) are generally incorporated to yield sufficiently high mechanical properties. As a drawback, the incorporation of reinforcing fillers typically causes processability problems due to high bulk viscosity of rubber compounds. Additionally, the high loading of reinforcing fillers could give negative results in some vulcanizate properties such as compression set and hysteresis loss (or heat build-up). As a consequence, novel reinforcing fillers with relatively high specific surface area and/or aspect ratio have been introduced, for example, nanoclay and carbon nanotubes (CNT). With the uses of such fillers, the filler loading required for any given properties could be markedly decreased while good dynamic mechanical properties of the rubber could still be preserved. By this means, a balance of processability, static and dynamic mechanical properties is possible. As one can expect, the difficulty in mixing is the major limitation for the utilization of the nanofillers [1]. CNT has gained much attention in the past 2 decades due to its extremely high mechanical strength and electrical conductivity and therefore is attractive to be used in a wide range of polymer composites [2-6]. It has been reported that, at a given modulus of composites, the required filler loading could be reduced remarkably by substituting the conventional fillers such as CB and PSi with CNT [7-9]. The uses of CNT as reinforcing fillers have been reported in both plastic and elastomeric matrices [10-16].

Although comparison of reinforcement magnitude between CNT and other fillers has been reported to some extent, most of works have been focused on nonpolar rubbers such as NR [17-19], EPDM [17], and SBR [20]. Consequently, 
TABLE 1: Physical characteristics of fillers.

\begin{tabular}{lcccc}
\hline Filler & Mean primary particle size $(\mathrm{nm})$ & BET specific surface area $\left(\mathrm{m}^{2} / \mathrm{g}\right)$ & DBPA $(\mathrm{mL} / 100 \mathrm{~g})$ & Density $\left(\mathrm{g} / \mathrm{cm}^{3}\right)$ \\
\hline MWCNT & 9.5 (outer diameter) & 286 & - & 420 \\
CCB & 30 & 1,103 & 114 & - \\
CB & $20-30$ & 111 & - & 2 \\
PSi & $10-30$ & 135 & -05 \\
\hline
\end{tabular}

TABLE 2: Compounding recipe.

\begin{tabular}{lc}
\hline Ingredient & Content (phr) \\
\hline NBR & 100 \\
Filler (MWCNT, CCB, CB, and PSi) & $0,5,10$, and 15 \\
Stearic acid & 0.5 \\
DCP & 2 \\
\hline
\end{tabular}

such comparison in polar rubbers including nitrile rubber is of interest. This study aims to compare the reinforcement efficiency of MWCNT with other conventional reinforcing fillers (i.e., CB, PSi, and CCB) in peroxide cured NBR by investigating viscoelastic behavior, mechanical properties, electrical properties, bound rubber content, and cross-link density of the rubber filled with these fillers.

\section{Experimental}

2.1. Materials. Nitrile rubber (NBR; N230SL) (acrylonitrile content of $35 \%$ and density $0.98 \mathrm{~g} / \mathrm{cm}^{3}$ ) was supplied by JSR (Japan). Multiwalled carbon nanotubes (MWCNT;

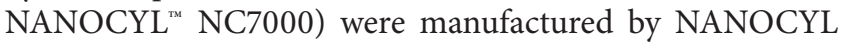
(Belgium). All other materials were supplied by suppliers or manufacturers in Thailand. Conductive carbon black (CCB; Printex XE2-B) was supplied by JJ-Degussa Hüls (Thailand). Carbon black (CB; N220) was manufactured by Thai Carbon Black PCL. Precipitated silica (PSi; Tokusil ${ }^{\circledR} 233$ ) was purchased from Tokuyama Siam Silica Co., Ltd. Details of filler characteristics have been reported elsewhere as tabulated in Table 1 [19, 21-27]. Commercial grade stearic acid and 98\% active dicumyl peroxide (DCP) were supplied by Chemmin Co., Ltd. and Petchthai Chemical Co., Ltd., respectively.

2.2. Composite Preparation. NBR compounds were prepared, according to the formulation given in Table 2, by two-roll mill at room temperature. NBR was initially masticated for 1 minute, and then stearic acid was added, followed by the filler (MWCNT, CCB, CB, or PSi). DCP was added at 15 th minute of the mixing cycle. The mixing was continued for another 5 minutes. A curing process of rubber compounds was conducted using a hot-press at $160^{\circ} \mathrm{C}$ with respect to the optimum cure time $\left(t_{c 90}\right)$ as predetermined from the moving die rheometer (MDR, MD+/Alpha Technologies, USA).

2.3. Characterization. Bound rubber content (BRC), a measure of rubber-filler interaction, was measured by immersing approximately $0.2 \mathrm{~g}$ of rubber compounds in $100 \mathrm{~mL}$ acetone for 7 days at room temperature. The insoluble fraction was then filtered and dried at $60^{\circ} \mathrm{C}$ until a constant weight was obtained. The calculation of BRC is illustrated in [28]

$$
\operatorname{BRC}(\%)=\frac{\left[w_{f g}-w_{t}\left(m_{f} /\left(m_{f}+m_{r}\right)\right)\right]}{w_{t}\left[m_{r} /\left(m_{f}+m_{r}\right)\right]} \times 100,
$$

where $w_{f g}$ is the weight of filler and gel after being dried, $w_{t}$ is the specimen weight before solvent immersion, and $m_{f}$ and $m_{r}$ are filler and rubber fractions in the compound, respectively.

Viscoelastic behavior of the cured samples was measured using a dynamic mechanical analyzer (Gabo Qualimeter model Eplexor $25 \mathrm{~N}$, Germany). Strain sweep tests were performed under tension mode with dynamic strain range of $0.01-10 \%$, frequency at $5 \mathrm{~Hz}$, and static strain of $10 \%$ at $25^{\circ} \mathrm{C}$. To determine the dynamic mechanical properties as a function of temperature, the test specimen was deformed sinusoidally at static and dynamic strain of $1 \%$ and $0.1 \%$, respectively, frequency of $10 \mathrm{~Hz}$ with a heating rate of $2^{\circ} \mathrm{C} / \mathrm{min}$.

Volume resistivity of the rubber was investigated by a Hall Effect Measurement System (Bridge Technologies model HMS 3000, USA). A conductive paste was applied on the specimen surface prior to testing in order to improve reliability of the test results.

Hardness test was performed using a Shore A durometer (Wallace model H17A, UK) as per ISO 7619-1. Tensile properties were measured using a universal mechanical tester (Instron model 5566, USA) based on ISO 37 (die type 1). Heat build-up of the NBR vulcanizates was determined by the Goodrich flexometer (BF Goodrich Model II, USA) under static load of $245 \mathrm{~N}$ at $100^{\circ} \mathrm{C}$, frequency of $30 \mathrm{~Hz}$, and dynamic deformation of $4.45 \mathrm{~mm}$. The volume loss or abrasion loss of the vulcanizates was determined using DIN abrasion tester (Zwick abrasion tester model 6120, Germany), according to ISO 4649.

Swelling test was used to determine the cross-link density of the NBR vulcanizates using the Flory-Rehner equation [29]. The test specimens with dimensions of approximately $1 \times 1 \times 0.2 \mathrm{~cm}^{3}$ were immersed in $100 \mathrm{~mL}$ acetone for 7 days. The weights of the test specimens before and after immersion were used to calculate the cross-link density as illustrated in

$$
n=-\frac{1}{2 V_{s}}\left(\frac{\ln \left(1-V_{r}\right)+V_{r}+\chi V_{r}^{2}}{V_{r}^{1 / 3}-\left(V_{r} / 2\right)}\right),
$$

where $n$ is the number of cross-links per unit volume $\left(\mathrm{mole} / \mathrm{cm}^{3}\right), V_{s}$ is the molar volume of acetone $(73.4 \mathrm{~mL} / \mathrm{mol})$ [30], $V_{r}$ is the volume fraction of rubber in swollen gel (\%), and $\chi$ is the NBR-acetone interaction parameter (0.349) [31]. 


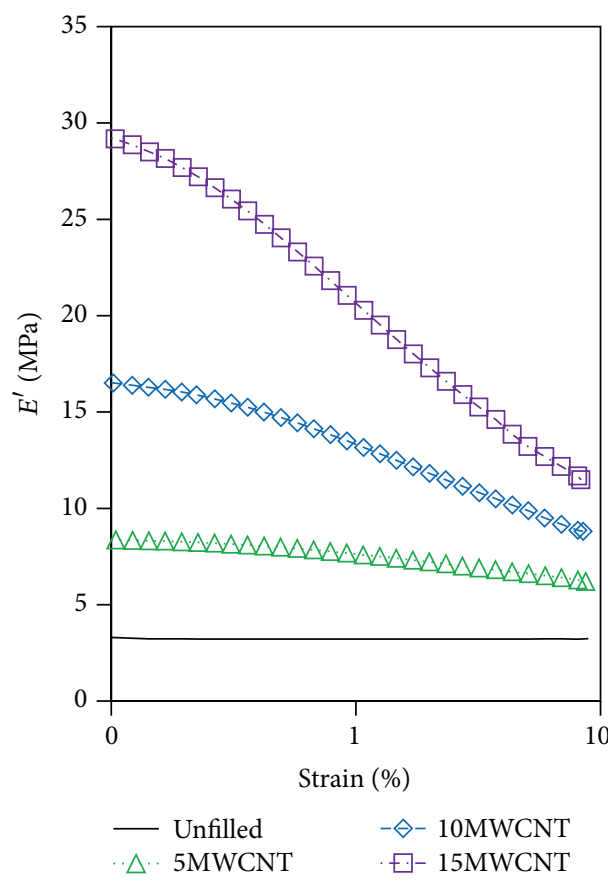

(a)

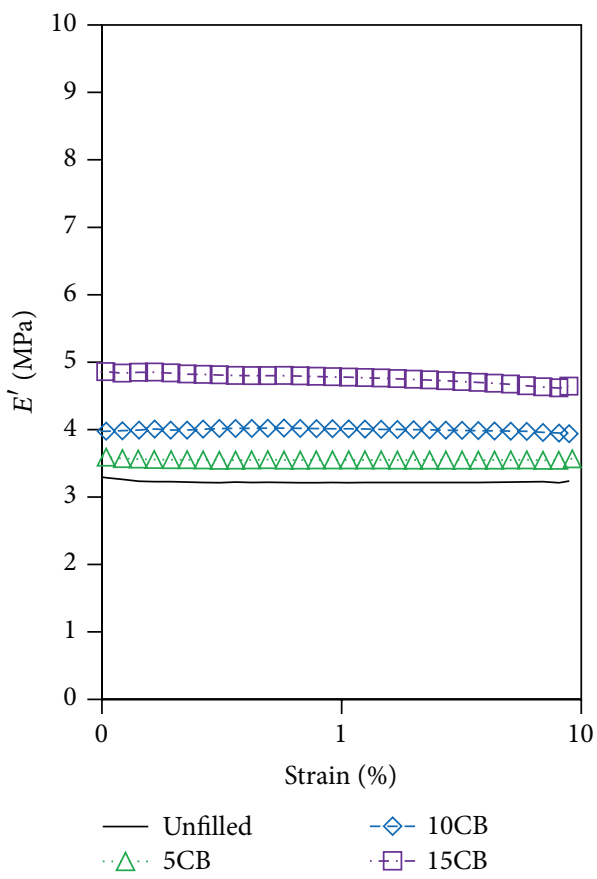

(c)

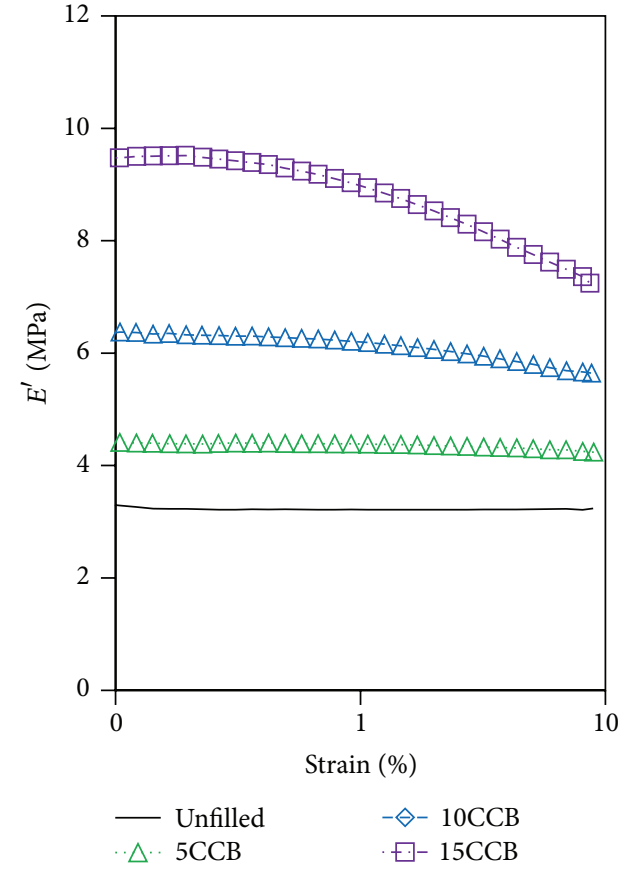

(b)

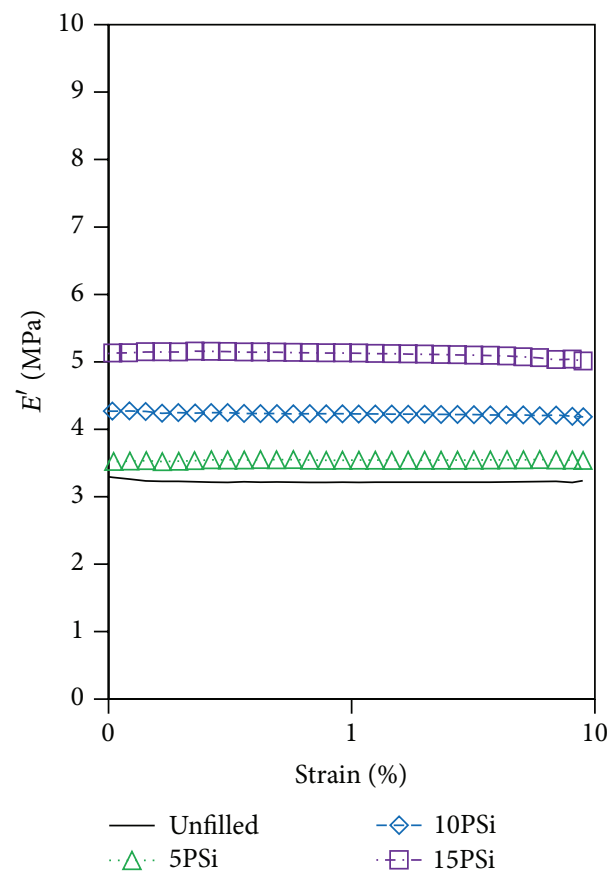

(d)

Figure 1: Strain sweep results of the NBR vulcanizates filled with different fillers: (a) MWCNT; (b) CCB; (c) CB; and (d) PSi.

The calculation of $V_{r}$ is exhibited in [32]

$$
V_{r}=\frac{m_{1} d_{s}}{m_{1}\left(d_{s}-d_{r}\right)+m_{2} d_{r}}
$$

where $m_{1}$ is the weight of rubber before swelling, $m_{2}$ is the weight of rubber after swelling, $d_{r}$ is the density of NBR $\left(0.98 \mathrm{~g} / \mathrm{cm}^{3}\right)$, and $d_{s}$ is the density of acetone $\left(0.79 \mathrm{~g} / \mathrm{cm}^{3}\right)$ [30].

\section{Results and Discussion}

The influences of filler type and loading on storage modulus as a function of strain are shown in Figure 1. Theoretically, there are four main factors governing $E^{\prime}$ : (i) filler-filler interaction, (ii) filler-rubber interaction, (iii) hydrodynamic effect, and (iv) rubber network. The magnitude of filler-filler interaction can be determined from the decrease in $E^{\prime}$ with 


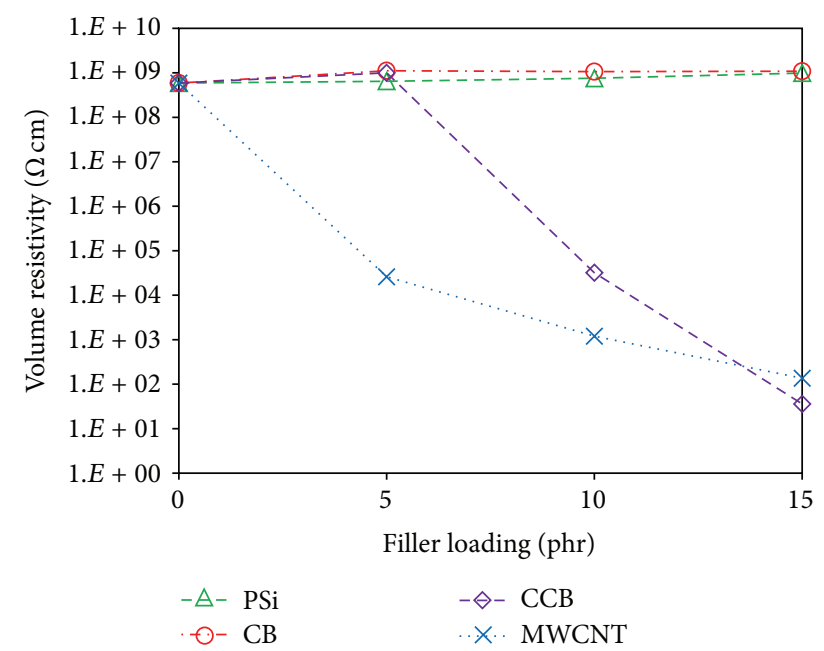

FIGURE 2: Electrical volume resistivity of the NBR vulcanizates filled with different fillers.

increasing strain. Obviously, for the MWCNT filled system, a formation of transient filler network could be observed even at relatively low filler loading ( $5 \mathrm{phr}$ ) and the magnitude of transient filler network is much more pronounced at higher loadings as evidenced by the higher $E^{\prime}$ at low strain. In the CCB filled system, the formation of transient filler network begins at $10 \mathrm{phr}$. However, at any given filler loading, the magnitude of filler network of the CCB filled system is considerably lower than that of the MWCNT filled system. For the CB and PSi filled systems, the magnitude of transient filler network is negligible throughout the filler loading range studied. The filler network formations found in the MWCNT and CCB filled systems are evidenced by electrical volume resistivity results as shown in Figure 2. It is generally accepted that the formation of filler network gives a sharp drop in electrical resistivity because when filler network is formed, the connected carbon black network is capable of carrying electrons leading to a dramatic change of conductivity [33, 34]. This point is widely known as a percolation threshold. Obviously, the sharp drop of electrical volume resistivity is found when MWCNT and CCB are incorporated at 5 and $10 \mathrm{phr}$, respectively. Due to the absence of filler network, the resistivity of the $\mathrm{CB}$ system is relatively unchanged even though the CB is incorporated up to $15 \mathrm{phr}$. Since PSi is not electrically conductive, predicting the level of PSi network formation is not possible using the measurement of electrical volume resistivity. The electrical volume resistivity of the PSi filled system is therefore relatively high and comparable to that of the unfilled system.

It could also be observed from Figure 3 that, at sufficiently high strain $(10 \%)$ where the filler network is believed to be fully destroyed, the MWCNT filled system still possesses the highest $E^{\prime}$, followed by the CCB, PSi, and CB filled systems, respectively. To explain the high magnitude of high-strain $E^{\prime}$ found in the MWCNT and CCB filled systems, there are three factors to be considered. The hydrodynamic effect, as typically caused by a dilution of deformable polymeric phase with an undeformable filler phase, is not very crucial and

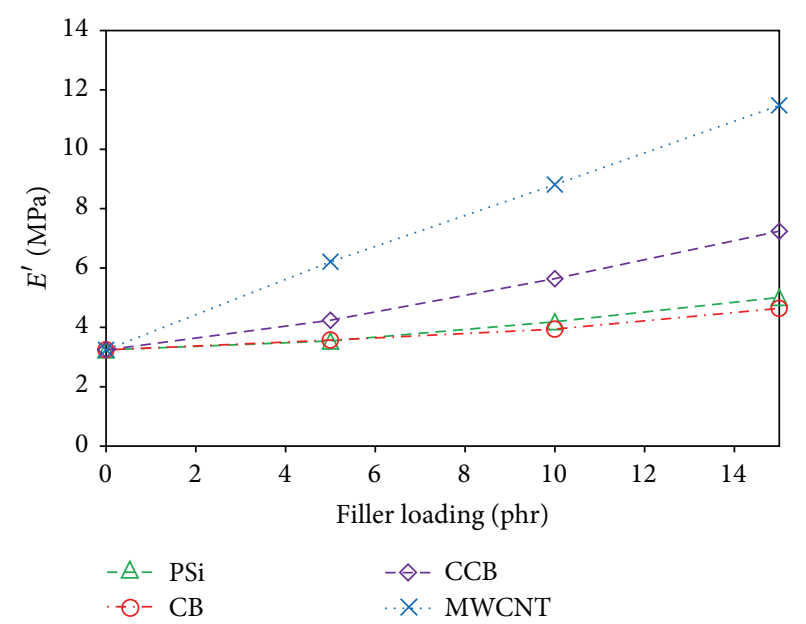

FIGURE 3: $E^{\prime}$ at $10 \%$ strain of the NBR vulcanizates filled with different fillers.

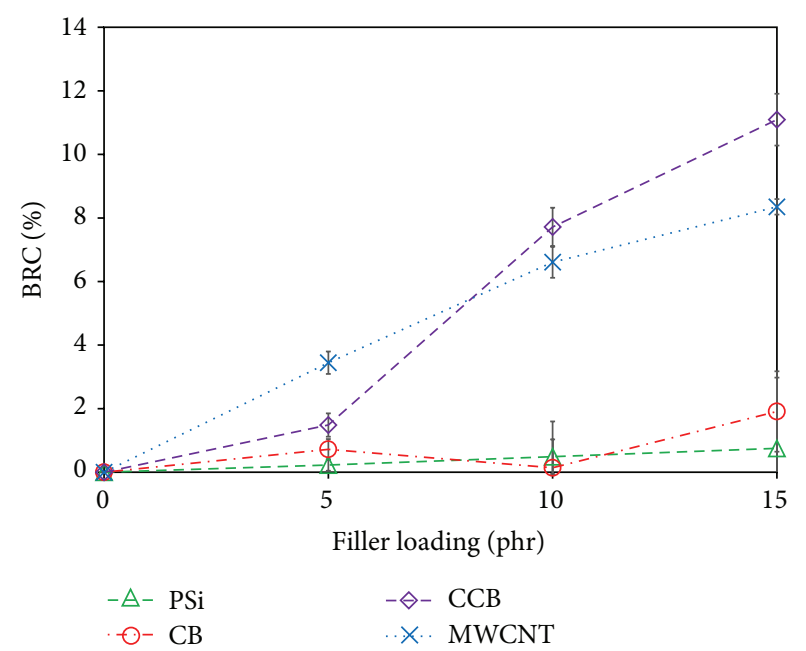

FIGURE 4: Bound rubber content (BRC) of the NBR compounds filled with different fillers.

could be neglected because all fillers employed herein have comparable density. Therefore, the dominant factors affecting the high-strain $E^{\prime}$ are (i) rubber-filler interaction and (ii) rubber network. Figure 4 shows the BRC results of the filledNBR compounds. Apparently, the CCB and MWCNT filled systems exhibit significantly higher BRC than the $\mathrm{CB}$ and PSi filled systems. At $5 \mathrm{phr}$, MWCNT yields the highest BRC, despite the inert surfaces of MWCNT [35]. The unexpectedly high BRC found at $5 \mathrm{phr}$ of MWCNT is believed to arise from the rubber trapped in MWCNT agglomerates and network. Although the BRC of the MWCNT filled system tends to increase continuously with increasing MWCNT loading, it is obvious that, at $10 \mathrm{phr}$ and above, the system incorporated with CCB gives higher BRC than that incorporated with MWCNT. The explanation is given by the higher filler structure and specific surface area of the CCB [22]. In addition, at sufficiently high loading $(\geq 10 \mathrm{phr})$ where network of CCB is formed, the rubber trapped in CCB network could also contribute to the high BRC. Although the CCB system 


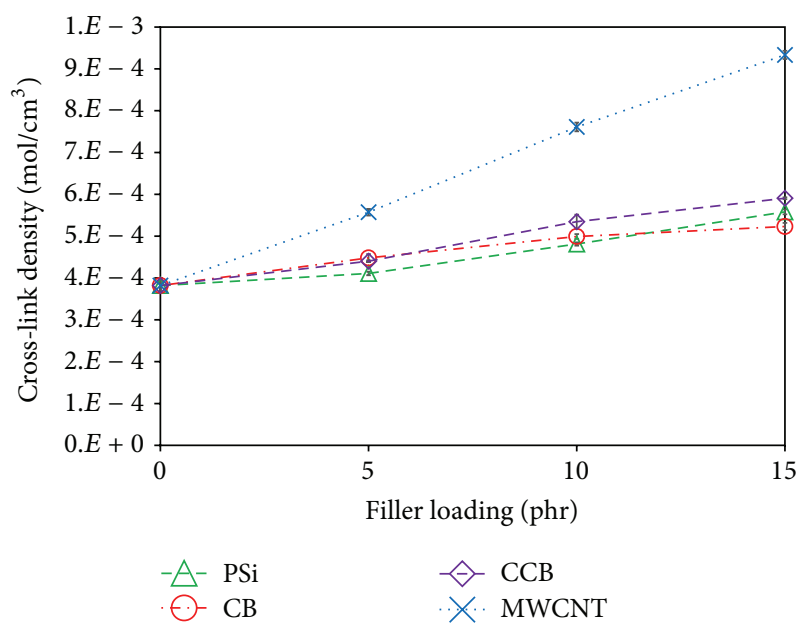

FIgURE 5: Cross-link density of the NBR vulcanizates filled with various fillers.

demonstrates the highest BRC and thus the rubber-filler interaction at $10 \mathrm{phr}$ or higher, the high-strain $E^{\prime}$ of this system is still lower than that of the MWCNT filled system at any filler loading (see Figure 1). This finding could be due to the highest cross-link density of the MWCNT filled system as evidenced by the cross-link density results calculated from the Flory-Rehner equation (Figure 5). However, it must be noted that the calculated cross-link density in this work includes not only the actual cross-link density of rubber network, but also the trapped and bound rubbers.

Regardless of the filler type, the cross-link density increases with increasing filler loading. The results are understandable as the magnitudes of trapped rubber and bound rubber increase with increasing filler loading. At any given loading, the MWCNT filled system represents the highest cross-link density followed by the CCB, PSi, and CB filled systems, respectively. The explanation is given to the greatest amount of trapped rubber in MWCNT network. It could be also observed that cross-link density of the MWCNT system as calculated from the Flory-Rehner equation is unexpectedly high particularly at high MWCNT loadings. This is probably due to the high extent of MWCNT network which is capable of resisting the solvent swelling of the rubber matrix.

Figure 6 shows the temperature-dependent $\tan \delta$ of the NBR vulcanizates. The damping peak $\left(\tan \delta_{\max }\right)$ of all vulcanizates is found at the temperature of approximately $-9^{\circ} \mathrm{C}$, regardless of filler type and loading. However, the $\tan \delta_{\max }$ and relative $\tan \delta$ area (as tabulated in Table 3) decrease with increasing filler loading due to the dilution effect, particularly in the MWCNT filled system containing the relatively high magnitude of trapped rubber, followed by CCB, PSi, and CB filled systems, respectively. Some authors have reported the relationship between $\tan \delta_{\max }$ of unfilled and filled rubber as shown in $[36,37]$

$$
\tan \delta_{m f}=\frac{\tan \delta_{m u}}{1+\beta \phi},
$$

where $\tan \delta_{m f}$ and $\tan \delta_{m u}$ represent maximum $\tan \delta$ of filled and unfilled systems, respectively; $\beta$ is a phenomenological
TABLE 3: Summary of dynamic viscoelastic response.

\begin{tabular}{lccccc}
\hline & Loading (phr) & MWCNT & CCB & CB & PSi \\
\hline \multirow{3}{*}{$\tan \delta_{\max }$} & 0 & 1.54 & 1.54 & 1.54 & 1.54 \\
& 5 & 1.12 & 1.38 & 1.50 & 1.51 \\
& 10 & 0.88 & 1.19 & 1.44 & 1.40 \\
& 15 & 0.7 & 0.99 & 1.38 & 1.32 \\
\hline \multirow{3}{*}{ Relative $\tan \delta$ area } & 0 & 1.00 & 1.00 & 1.00 & 1.00 \\
& 5 & 0.80 & 0.94 & 0.99 & 1.00 \\
& 10 & 0.66 & 0.85 & 0.97 & 0.95 \\
$\beta \phi^{*}$ & 15 & 0.55 & 0.74 & 0.94 & 0.93 \\
\hline \multirow{3}{*}{} & 0 & 0 & 0 & 0 & 0 \\
& 5 & 0.38 & 0.12 & 0.03 & 0.02 \\
& 10 & 0.75 & 0.29 & 0.07 & 0.10 \\
& 15 & 1.20 & 0.56 & 0.12 & 0.17 \\
\hline
\end{tabular}

${ }^{*}$ Calculated from (4).

interaction parameter determining the interfacial interaction of filler and matrix; $\phi$ is an effective volume fraction of filler; the $\beta \phi$ values as illustrated in Table 3 demonstrate the combination of interfacial interaction strength and effective volume fraction. As expected, the MWCNT filled system shows the highest $\beta \phi$ value which is considerably higher than those of the CCB, CB, and PSi. However, due to the poor interaction between MWCNT and rubber as a result of inert surfaces of MWCNT, the $\beta \phi$ value is dominated by the effective volume fraction. The $\beta \phi$ values of the $\mathrm{CCB}$ filled system are higher than those of the CB and PSi filled systems because the CCB possesses higher specific surface area and structure. Also, at the temperature range of $20-70^{\circ} \mathrm{C}$, the MWCNT filled system shows the highest $\tan \delta$ despite its highest cross-link density. The poor interfacial interaction and the high magnitude of MWCNT network are responsible for such highest magnitude of energy dissipation. On the other hand, the $\tan \delta$ values of the CB and PSi filled systems are comparable and relatively low, compared with that of the MWCNT filled system. This is mainly attributed to the lower specific surface area and lower level of filler network of $\mathrm{CB}$ and PSi.

Table 4 shows mechanical properties of the NBR vulcanizates. Regardless of the filler type, most mechanical properties such as tensile strength, modulus, and hardness are continuously improved with increasing filler loading. Also, the degree of reinforcement depends greatly on the filler characteristics; that is, MWCNT gives the highest level of reinforcement, followed by CCB, whereas both PSi and CB show the lowest level of reinforcement. Greater reinforcement of MWCNT over other conventional reinforcing fillers is in agreement with previous work [10, 18, 38]. Compared to the unfilled system, the abrasion loss of the filled systems decreases with increasing filler loading, mainly attributed to the dilution effect and the increased cross-link density and thus modulus and hardness. At any given filler loading, both CCB and MWCNT filled systems possess markedly greater abrasion resistance than the CB and PSi filled systems. This is the consequence of the greater magnitudes of modulus, cross-link density, and hardness as discussed earlier. The 

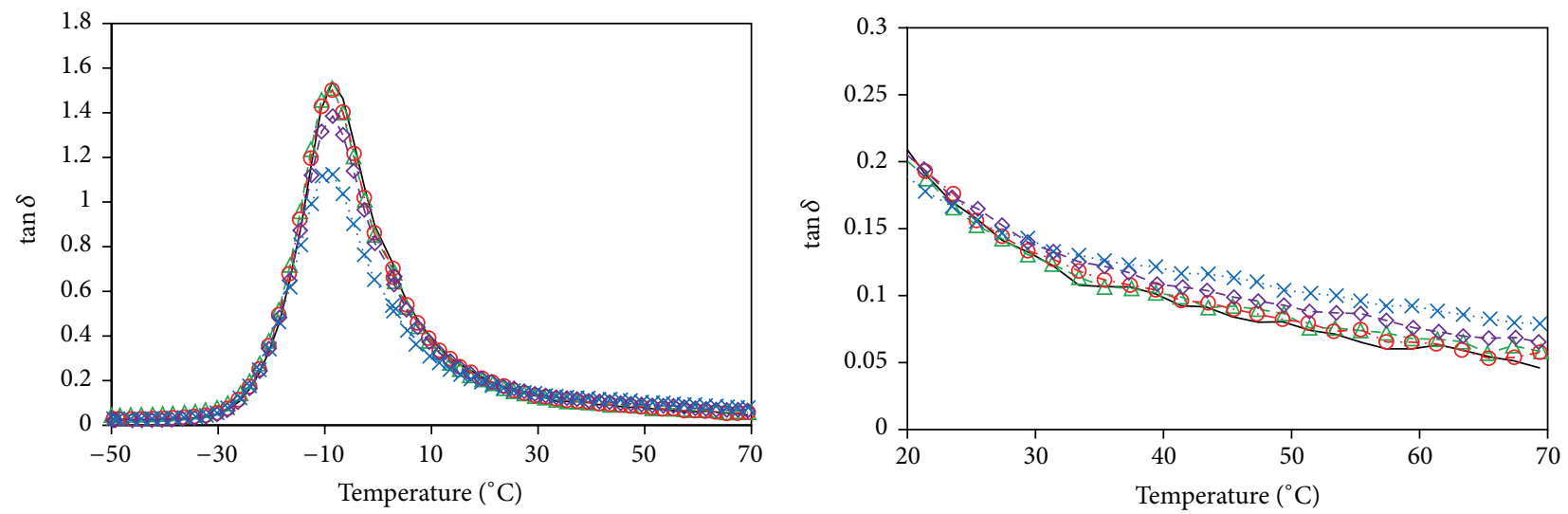
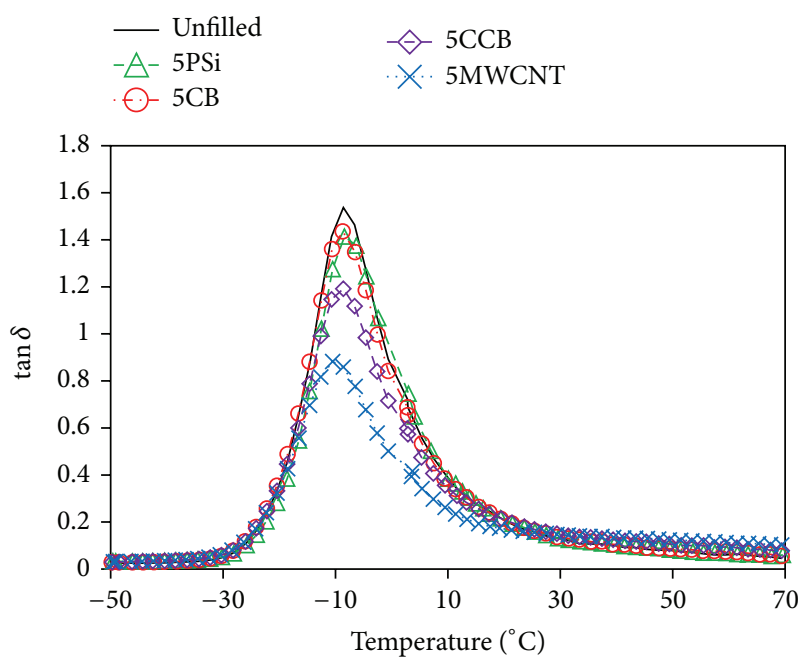

$\begin{array}{ll}- \text { Unfilled } & \diamond 10 \mathrm{CCB} \\ -\mathrm{A}-10 \mathrm{PSi} & \ngtr 10 \mathrm{MWCNT} \\ \ominus-10 \mathrm{CB} & \ngtr\end{array}$

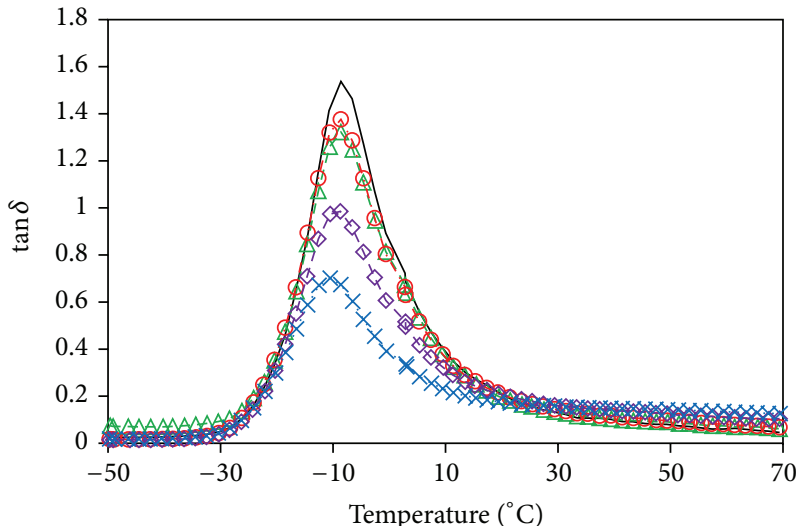

$\begin{array}{ll}- \text { Unfilled } & -15 \mathrm{CCB} \\ -\mathrm{A}-15 \mathrm{PSi} & \ngtr 15 \mathrm{MWCNT} \\ \ominus-15 \mathrm{CB} & -1\end{array}$

(a)
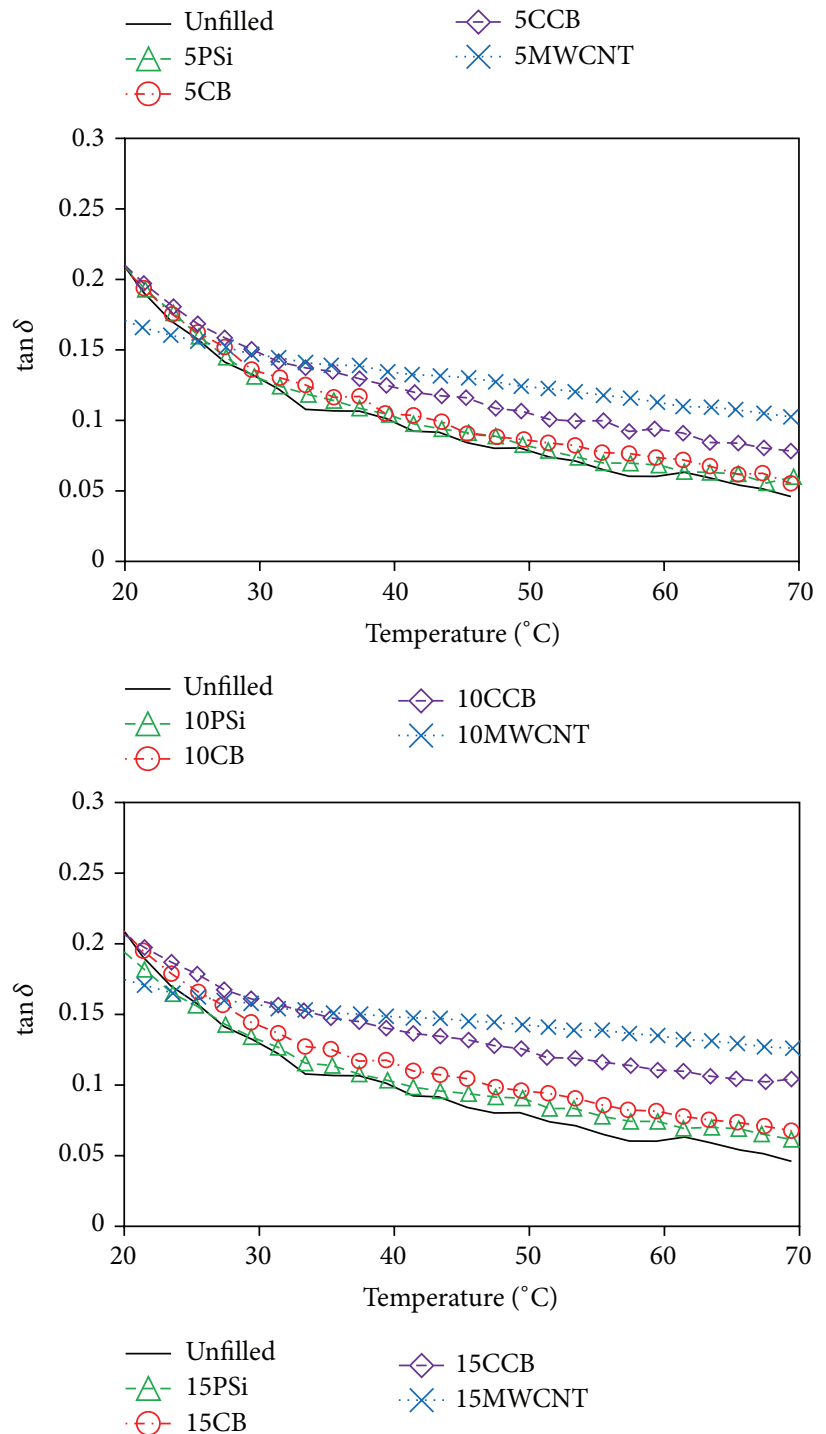

(b)

FIGURE 6: $\tan \delta$ values of the NBR vulcanizates filled with different fillers: (a) temperature range of $-50-70^{\circ} \mathrm{C}$; (b) enlarged temperature range of $20-70^{\circ} \mathrm{C}$. 
TABLE 4: Mechanical properties of NBR vulcanizates.

\begin{tabular}{|c|c|c|c|c|c|}
\hline Properties & Loading (phr) & MWCNT & $\mathrm{CCB}$ & $\mathrm{CB}$ & PSi \\
\hline \multirow{4}{*}{ Tensile strength (MPa) } & 0 & $2.9 \pm 0.37$ & $2.9 \pm 0.4$ & $2.9 \pm 0.4$ & $2.9 \pm 0.4$ \\
\hline & 5 & $8.6 \pm 0.1$ & $4.3 \pm 0.1$ & $4.1 \pm 0.2$ & $3.6 \pm 0.4$ \\
\hline & 10 & $12.9 \pm 0.4$ & $9.1 \pm 0.2$ & $5.3 \pm 0.5$ & $3.8 \pm 0.2$ \\
\hline & 15 & $17.7 \pm 0.5$ & $14.6 \pm 0.6$ & $8.5 \pm 1.5$ & $5.3 \pm 0.3$ \\
\hline \multirow{4}{*}{ Elongation at break (\%) } & 0 & $182 \pm 14$ & $182 \pm 14$ & $182 \pm 14$ & $182 \pm 14$ \\
\hline & 5 & $176 \pm 2$ & $196 \pm 3$ & $202 \pm 10$ & $210 \pm 17$ \\
\hline & 10 & $178 \pm 3$ & $244 \pm 2$ & $217 \pm 14$ & $220 \pm 1$ \\
\hline & 15 & $171 \pm 6$ & $277 \pm 6$ & $231 \pm 14$ & $218 \pm 10$ \\
\hline \multirow{4}{*}{ Modulus at $100 \%(\mathrm{MPa})$} & 0 & $1.73 \pm 0.04$ & $1.73 \pm 0.04$ & $1.73 \pm 0.04$ & $1.73 \pm 0.04$ \\
\hline & 5 & $5.04 \pm 0.09$ & $1.93 \pm 0.02$ & $1.82 \pm 0.10$ & $1.79 \pm 0.06$ \\
\hline & 10 & $7.49 \pm 0.56$ & $2.47 \pm 0.07$ & $1.79 \pm 0.05$ & $1.75 \pm 0.06$ \\
\hline & 15 & $11.28 \pm 0.35$ & $3.30 \pm 0.27$ & $2.15 \pm 0.10$ & $2.30 \pm 0.12$ \\
\hline \multirow{4}{*}{ Hardness (Shore A) } & 0 & $53.3 \pm 0.3$ & $53.3 \pm 0.3$ & $53.3 \pm 0.3$ & $53.3 \pm 0.3$ \\
\hline & 5 & $61.8 \pm 0.3$ & $56.0 \pm 0.0$ & $55.3 \pm 0.3$ & $54.8 \pm 0.8$ \\
\hline & 10 & $69.0 \pm 0.5$ & $61.7 \pm 0.6$ & $56.5 \pm 0.9$ & $56.8 \pm 1.0$ \\
\hline & 15 & $69.3 \pm 0.8$ & $65.5 \pm 0.5$ & $58.2 \pm 0.3$ & $59.9 \pm 0.8$ \\
\hline \multirow{4}{*}{ Heat build-up $\left({ }^{\circ} \mathrm{C}\right)$} & 0 & $7.5 \pm 0.7$ & $7.5 \pm 0.7$ & $7.5 \pm 0.7$ & $7.5 \pm 0.7$ \\
\hline & 5 & $11.5 \pm 0.7$ & $9.0 \pm 0.0$ & $8.0 \pm 0.0$ & $8.0 \pm 0.0$ \\
\hline & 10 & $18.5 \pm 0.7$ & $14.0 \pm 0.0$ & $9.0 \pm 0.0$ & $9.0 \pm 0.0$ \\
\hline & 15 & $29.0 \pm 1.4$ & $21.0 \pm 0.0$ & $10.5 \pm 0.7$ & $10.0 \pm 0.0$ \\
\hline \multirow{4}{*}{ Abrasion loss $\left(\mathrm{mm}^{3}\right)$} & 0 & $250.7 \pm 10.8$ & $250.7 \pm 10.8$ & $250.7 \pm 10.8$ & $250.7 \pm 10.8$ \\
\hline & 5 & $82.0 \pm 12.7$ & $91.4 \pm 10.0$ & $188.2 \pm 4.7$ & $171.2 \pm 25.0$ \\
\hline & 10 & $54.2 \pm 3.7$ & $54.9 \pm 3.1$ & $132.6 \pm 12.6$ & $155.7 \pm 8.8$ \\
\hline & 15 & $48.0 \pm 2.6$ & $53.3 \pm 1.3$ & $90.8 \pm 6.3$ & $127.7 \pm 9.9$ \\
\hline
\end{tabular}

heat build-up test results also agree well with the $\tan \delta$ results as discussed previously; that is, the heat build-up increases consistently with increasing filler loading. At a given filler loading, the MWCNT filled system shows the highest temperature rise due to its relatively high magnitude of filler network and poor filler-rubber interfacial interaction [22, 38, 39]. However, except for the MWCNT filled system, the elongation at break appears to increase with increasing filler loading. Such increase is believed to be due to the slippage of un-cross-linked rubber molecules around filler particles which increases the specimen volume under high extension [40].

\section{Conclusions}

MWCNT shows the greatest reinforcing efficiency as evidenced by the sharp increases in tensile strength, 100\% modulus, hardness, and abrasion resistance of the NBR vulcanizates. The presence of MWCNT also leads to the significant reduction of volume resistivity even at very low filler loading $(5 \mathrm{phr})$. However, due to its poor interfacial interaction and high magnitude of filler network, the addition of MWCNT results in poor dynamic mechanical properties and thus high magnitudes of $\tan \delta$ and heat build-up. Despite its highest specific surface area, the reinforcing efficiency of CCB is slightly inferior to that of MWCNT. However, CCB still gives higher reinforcement than $\mathrm{CB}$ and PSi.

\section{Conflict of Interests}

The authors declare that there is no conflict of interests regarding the publication of this paper.

\section{Acknowledgments}

The authors gratefully acknowledge the financial support of the Center of Excellence for Innovation in Chemistry (PERCH-CIC). Sincere appreciation is also extended to the Rubber Technology Research Centre (RTEC), Mahidol University, and National Metal and Materials Technology Center (MTEC) for supporting the materials and test equipment.

\section{References}

[1] S. Thomas and R. Stephen, Rubber Nanocomposites, John Wiley \& Sons, New York, NY, USA, 2010.

[2] R. H. Baughman, A. A. Zakhidov, and W. A. de Heer, "Carbon nanotubes-the route toward applications," Science, vol. 297, no. 5582, pp. 787-792, 2002.

[3] J. N. Coleman, U. Khan, W. J. Blau, and Y. K. Gun'ko, "Small but strong: a review of the mechanical properties of carbon nanotube-polymer composites," Carbon, vol. 44, no. 9, pp. 16241652, 2006.

[4] V. N. Popov, "Carbon nanotubes: properties and application," Materials Science and Engineering: R: Reports, vol. 43, no. 3, pp. 61-102, 2004. 
[5] S. Iijima, "Helical microtubules of graphitic carbon," Nature, vol. 354, no. 6348, pp. 56-58, 1991.

[6] S. Rooj, A. Das, K. W. Stöckelhuber, D.-Y. Wang, V. Galiatsatos, and G. Heinrich, "Understanding the reinforcing behavior of expanded clay particles in natural rubber compounds," Soft Matter, vol. 9, no. 14, pp. 3798-3808, 2013.

[7] M. A. L. Manchado, L. Valentini, J. Biagiotti, and J. M. Kenny, "Thermal and mechanical properties of single-walled carbon nanotubes-polypropylene composites prepared by melt processing," Carbon, vol. 43, no. 7, pp. 1499-1505, 2005.

[8] R. Andrews and M. C. Weisenberger, "Carbon nanotube polymer composites," Current Opinion in Solid State and Materials Science, vol. 8, no. 1, pp. 31-37, 2004.

[9] L. Bokobza, "Multiwall carbon nanotube elastomeric composites: a review," Polymer, vol. 48, no. 17, pp. 4907-4920, 2007.

[10] M. A. López-Manchado, J. Biagiotti, L. Valentini, and J. M. Kenny, "Dynamic mechanical and Raman spectroscopy studies on interaction between single-walled carbon nanotubes and natural rubber," Journal of Applied Polymer Science, vol. 92, no. 5, pp. 3394-3400, 2004.

[11] L. D. Perez, M. A. Zuluaga, T. Kyu, J. E. Mark, and B. L. Lopez, "Preparation, characterization, and physical properties of multiwall carbon nanotube/elastomer composites," Polymer Engineering and Science, vol. 49, no. 5, pp. 866-874, 2009.

[12] P. Pötschke, T. D. Fornes, and D. R. Paul, "Rheological behavior of multiwalled carbon nanotube/polycarbonate composites," Polymer, vol. 43, no. 11, pp. 3247-3255, 2002.

[13] D. Qian, E. C. Dickey, R. Andrews, and T. Rantell, "Load transfer and deformation mechanisms in carbon nanotube-polystyrene composites," Applied Physics Letters, vol. 76, no. 20, pp. $2868-$ 2870, 2000.

[14] M. S. P. Shaffer and A. H. Windle, "Fabrication and characterization of carbon nanotube/poly(vinyl alcohol) composites," Advanced Materials, vol. 11, no. 11, pp. 937-941, 1999.

[15] L. Vaisman, E. Wachtel, H. D. Wagner, and G. Marom, "Polymer-nanoinclusion interactions in carbon nanotube based polyacrylonitrile extruded and electrospun fibers," Polymer, vol. 48, no. 23, pp. 6843-6854, 2007.

[16] P. Verge, S. Peeterbroeck, L. Bonnaud, and P. Dubois, "Investigation on the dispersion of carbon nanotubes in nitrile butadiene rubber: role of polymer-to-filler grafting reaction," Composites Science and Technology, vol. 70, no. 10, pp. 1453-1459, 2010.

[17] H. Lorenz, J. Fritzsche, A. Das et al., "Advanced elastomer nanocomposites based on CNT-hybrid filler systems," Composites Science and Technology, vol. 69, no. 13, pp. 2135-2143, 2009.

[18] L. Bokobza and M. Kolodziej, "On the use of carbon nanotubes as reinforcing fillers for elastomeric materials," Polymer International, vol. 55, no. 9, pp. 1090-1098, 2006.

[19] P. Thaptong, C. Sirisinha, U. Thepsuwan, and P. Sae-Oui, "Properties of natural rubber reinforced by carbon black-based hybrid fillers," Polymer-Plastics Technology and Engineering, vol. 53, no. 8, pp. 818-823, 2014.

[20] L. Bokobza and C. Belin, "Effect of strain on the properties of a styrene-butadiene rubber filled with multiwall carbon nanotubes," Journal of Applied Polymer Science, vol. 105, no. 4, pp. 2054-2061, 2007.

[21] A. Schröder, M. Klüppel, R. H. Schuster, and J. Heidberg, "Surface energy distribution of carbon black measured by static gas adsorption," Carbon, vol. 40, no. 2, pp. 207-210, 2002.

[22] S. A. Nanocyl, Nanocyl NC7000 Series-Product Datasheet-Thin Multi-Walled Carbon Nanotubes, Nanocyl S. A., Sambreville, Belgium, 2009.
[23] M. M. Saatchi and A. Shojaei, "Mechanical performance of styrene-butadiene-rubber filled with carbon nanoparticles prepared by mechanical mixing," Materials Science and Engineering: $A$, vol. 528, no. 24, pp. 7161-7172, 2011.

[24] J. B. Donnet, Carbon Black: Science and Technology, CRC Press, New York, NY, USA, 1993.

[25] H. S. Katz and J. Mileski, Handbook of Fillers for Plastics, Springer Science \& Business Media, 1987.

[26] B. P. Grady, Carbon Nanotubes-Polymer Composites: Manufacture, Properties and Application, John Wiley \& Sons, 2011.

[27] N. Hewitt and P. Ciullo, Compounding Precipitated Silica in Elastomers: Theory and Practice, William Andrew, 2007.

[28] S. S. Choi, "Difference in bound rubber formation of silica and carbon black with styrene-butadiene rubber," Polymers for Advanced Technologies, vol. 13, no. 6, pp. 466-474, 2002.

[29] P. J. Flory and J. Rehner, "Statistical mechanics of cross-linked polymer networks II. Swelling," The Journal of Chemical Physics, vol. 11, no. 11, pp. 521-526, 1943.

[30] R. L. Myers, The 100 Most Important Chemical Compounds: A Reference Guide, Greenwood Press, 2007.

[31] B. C. Guo, F. Chen, W. W. Chen, Y. D. Lei, and D. M. Jia, "Reinforcement of nitrile rubber by in situ formed zinc disorbate," Express Polymer Letters, vol. 4, no. 9, pp. 529-538, 2010.

[32] M. Barlkani and C. Hepburn, "Determination of crosslink density by swelling in the castable polyurethane elastomer based on 1/4-cyclohexane diisocyanate and para-phenylene diisocyanate," Iranian Journal of Polymer Science \& Technology, vol. 1, no. 1, pp. 1-5, 1992.

[33] I. Balberg, N. Binenbaum, and N. Wagner, "Percolation thresholds in the three-dimensional sticks system," Physical Review Letters, vol. 52, no. 17, pp. 1465-1468, 1984.

[34] D. Stauffer, Introduction to Percolation Theory, Taylor \& Francis, Abingdon, UK, 1992.

[35] K. A. Wepasnick, B. A. Smith, J. L. Bitter, and D. Howard Fairbrother, "Chemical and structural characterization of carbon nanotube surfaces," Analytical and Bioanalytical Chemistry, vol. 396, no. 3, pp. 1003-1014, 2010.

[36] L. Qu, G. Yu, X. Xie, L. Wang, J. Li, and Q. Zhao, "Effect of silane coupling agent on filler and rubber interaction of silica reinforced solution styrene butadiene rubber," Polymer Composites, vol. 34, no. 10, pp. 1575-1582, 2013.

[37] K. D. Ziegel and A. Romanov, "Modulus reinforcement in elastomer composites. I. Inorganic fillers," Journal of Applied Polymer Science, vol. 17, no. 4, pp. 1119-1131, 1973.

[38] P. Sae-Oui, U. Thepsuwan, P. Thaptong, and C. Sirisinha, "Comparison of reinforcing efficiency of carbon black, conductive carbon black, and carbon nanotube in natural rubber," Advances in Polymer Technology, vol. 33, no. 4, 2014.

[39] C. Nah, J. Y. Lim, B. H. Cho, C. K. Hong, and A. N. Gent, "Reinforcing rubber with carbon nanotubes," Journal of Applied Polymer Science, vol. 118, no. 3, pp. 1574-1581, 2010.

[40] Y. Fukahori, "New progress in the theory and model of carbon black reinforcement of elastomers," Journal of Applied Polymer Science, vol. 95, no. 1, pp. 60-67, 2005. 

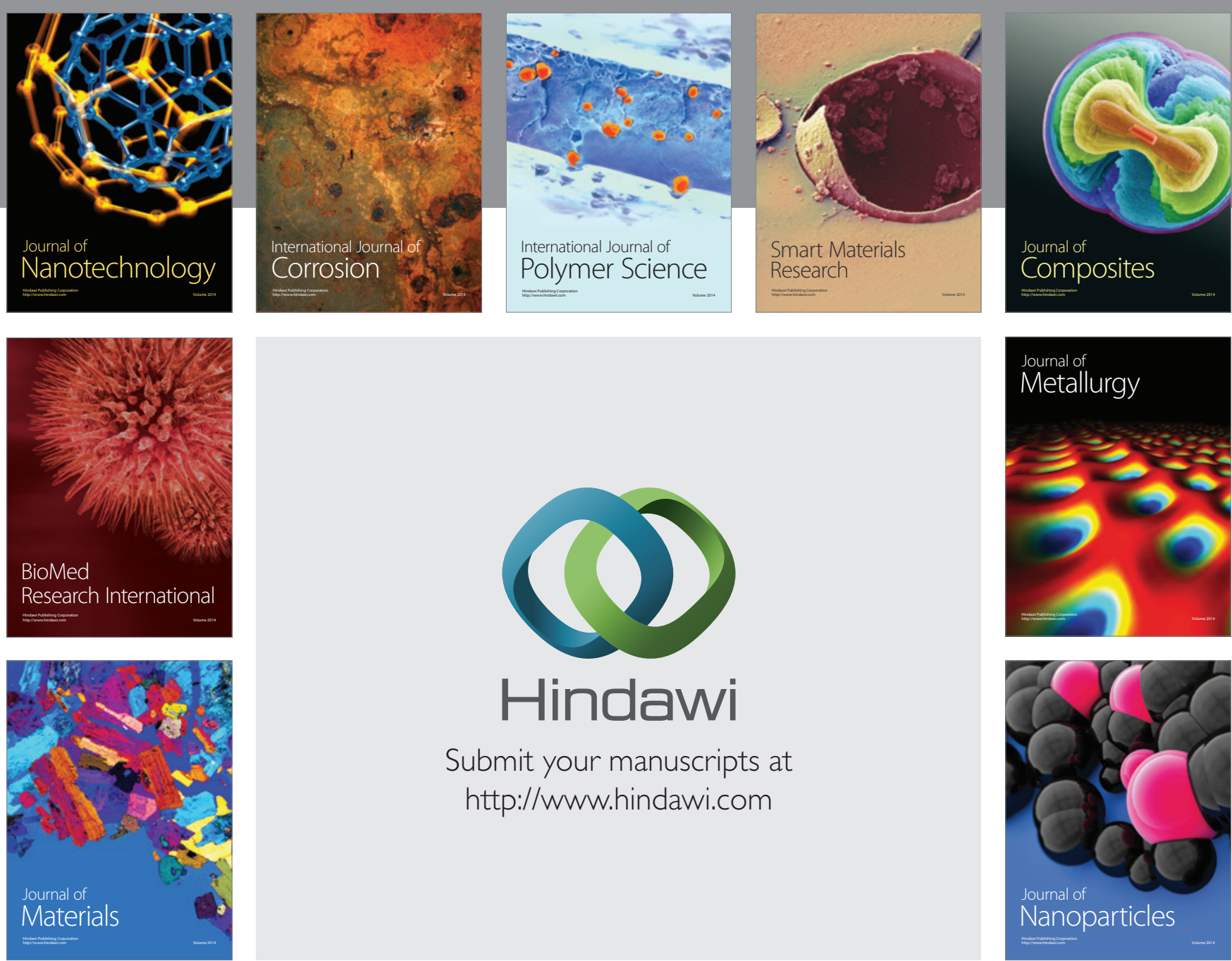

\section{Hindawi}

Submit your manuscripts at

http://www.hindawi.com

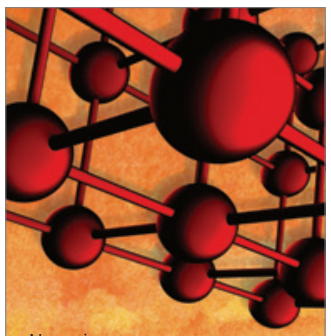

Materials Science and Engineering
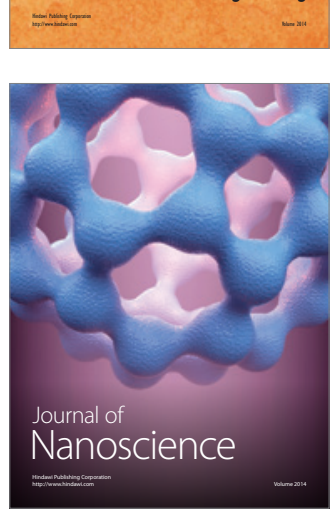
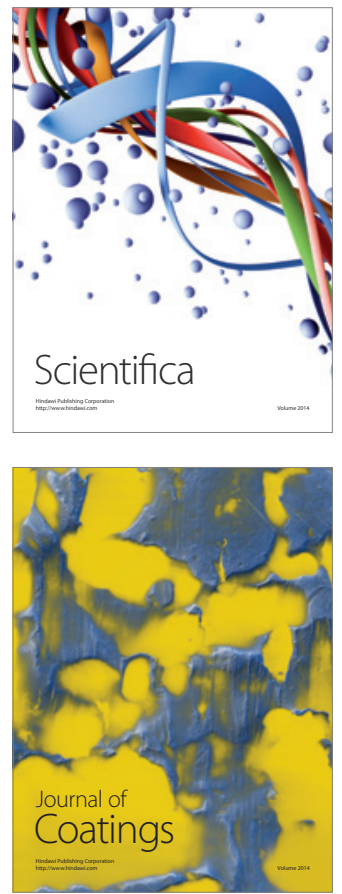
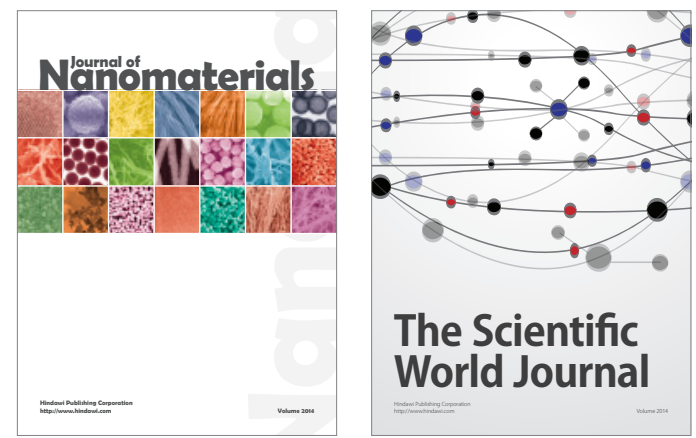

The Scientific World Journal
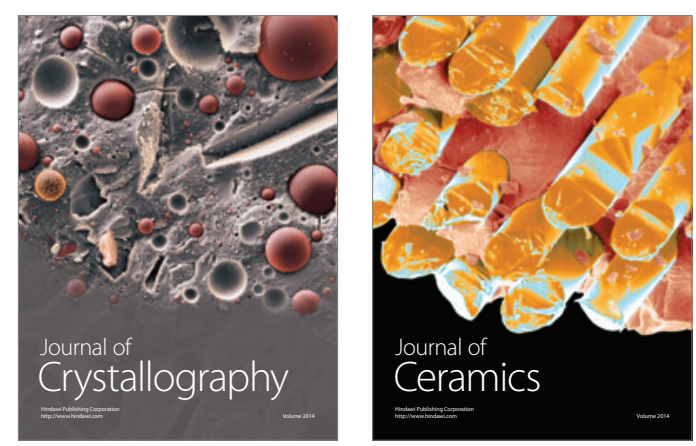
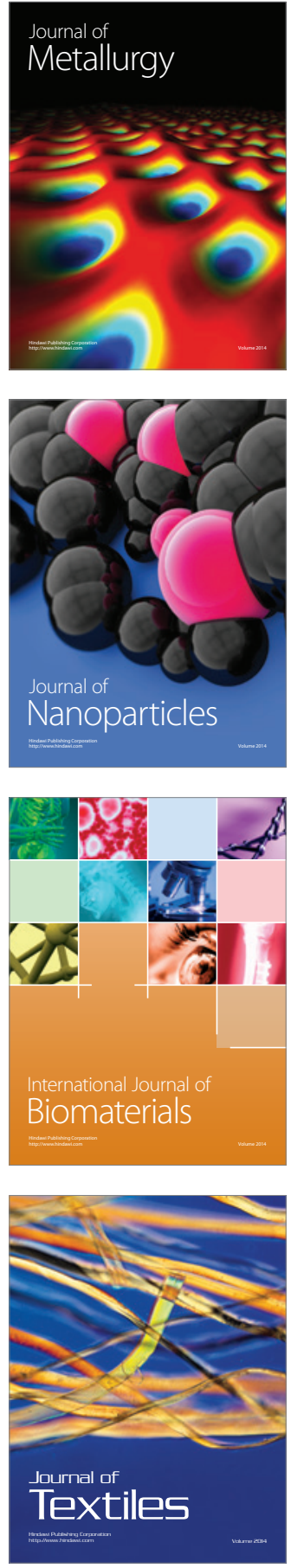